\title{
DIREITOS E GARANTIAS ÀS PESSOAS COM DEFICIÊNCIA: A ATUAÇÃO DO PODER PÚBLICO MUNICIPAL NO PROCESSO DE INCLUSÃO
}

\author{
Francisco Rodrigues Neto ${ }^{1}$, Daniela Leal ${ }^{2}$ \\ ${ }^{1}$ Especialista em Educação Física pelas Faculdades Integradas Padre Albino (FIPA-SP). Mestrando em Educação pelo Centro Universitário Moura \\ Lacerda, Ribeirão Preto, SP. E-mail: francisco.neto01@hotmail.com \\ ${ }^{2}$ Doutora em Psicologia da Educação pela Pontifícia Universidade Católica - PUC-SP. Professora do Programa de Pós-Graduação em Educação do \\ Centro Universitário Moura Lacerda, Ribeirão Preto, SP.
}

\section{RESUMO}

No ano de 2008, São Paulo se tornou o primeiro Estado brasileiro a implementar uma Secretaria Estadual para tratar de assuntos ligados à pessoa com deficiência. Entre suas principais ações destaca-se à política de implantação de instâncias executivas municipais (secretarias, coordenadorias, diretorias e assessorias), com objetivo de fortalecer as políticas de inclusão da pessoa com deficiência em todo o Estado. Nesse sentido, objetiva-se neste artigo apresentar algumas considerações sobre as contribuições das políticas públicas do Estado de São Paulo referentes ao processo de inclusão das pessoas com deficiência e sua implementação nos municípios paulistas, pelo viés da Educação. Para tanto, optou-se por uma pesquisa qualitativa, do tipo documental, caracterizada pela análise de leis, decretos, tratados e convenções, nacionais e internacionais, relacionados à garantia de direitos da pessoa com deficiência. Dos 152 municípios que seguiram a recomendação do Estado e implementaram instâncias específicas à Pessoa com Deficiência, encontra-se a parceria realizada entre as esferas governamentais do estado e do município, realizada no município de Catanduva, localizado na região noroeste do Estado de São Paulo, a 387 quilômetros da capital. Pode-se dizer que, por meio do incentivado da Secretaria de Estado dos Direitos das Pessoas com Deficiência, na última década, o município se tornou exemplo de boas práticas no que diz respeito à promoção da inclusão Social das pessoas com deficiência, através da implantação de importantes projetos e programas em diferentes áreas.

Palavras-chave: Política Pública; Estado; Município; Pessoa com deficiência. Inclusão.

\section{RIGHTS AND GUARANTEES FOR DISABLED PEOPLE: THE MUNICIPAL PUBLIC AUTHORITY IN THE INCLUSION PROCESS}

\begin{abstract}
In 2008, São Paulo became the first Brazilian State to implement a State Secretariat to deal with issues related to people with disabilities. Among its main actions is the policy of implementing municipal executive instances (Secretariat, Coordination, Executive Board, Advisory), with the objective of strengthening policies for the inclusion of persons with disabilities throughout the State. In this sense, the objective of this research is to identify the contribution of the public policies of the State of São Paulo regarding the process of inclusion of people with disabilities and its implementation in the municipalities of São Paulo, through the Education bias. For that, a qualitative, documentary type of study was chosen, characterized by the analysis of laws, decrees, treaties and conventions, national and international, related to guaranteeing the rights of persons with disabilities. The partial results indicate that, 152 municipalities followed the recommendation of the State and implemented specific instances to the Person with Disability. An example of partnership between the state and municipal government spheres is the one carried out by Catanduva municipality located in the northwest region of the State of São Paulo, 387 kilometers from the capital, which, encouraged by the State Secretariat for the Rights of Persons with Disabilities, in the last decade, the municipality has become an example of good practices regarding the promotion and social inclusion of people with disabilities, through the implementation of important projects and programs in different areas.
\end{abstract}

Keywords: Public Policy; State; County; People with disabilities; Inclusion. 


\section{INTRODUÇÃO}

Nas duas últimas décadas, principalmente, têm se observado um significativo aumento das ações elou Políticas Públicas voltadas à Promoção e Inclusão Social das Pessoas com Deficiência no Brasil e no Mundo. Tal fato, está diretamente ligado aos constantes avanços da medicina, programas de reabilitação física, tecnologias assistivas, educação, acessibilidade e exposição do tema nos diferentes meios de comunicação, bem como reflexo da atuação do Poder Público em suas diferentes esferas (Federal, Estadual e Municipal) responsáveis diretos pela elaboração, planejamento, implementação e operacionalização de Legislações e projetos que visem garantir às pessoas com deficiência seus direitos, possibilitando à inclusão da mesma.

Apesar dos avanços mencionados, a realidade ainda está bem distante de ser considerada a ideal para aproximadamente 1 bilhão de pessoas em todo o mundo, como aponta o Relatório Mundial sobre a Deficiência de 2012. Destacando que, deste 1 bilhão, aproximadamente 45,6 milhões são de brasileiros, segundo o IBGE (2010), revelando que, ainda, há muito o que ser feito sobretudo pelo Poder Público para atender a esse número de pessoas com deficiência, auxiliando-as a transpor as inúmeras barreiras para ter acesso aos direitos básicos e fundamentais como educação, saúde, emprego e renda, esporte e lazer, cultura e até mesmo o ir e vir com autonomia.

Todavia, não é de hoje que as pessoas com deficiência são vítimas de preconceito e discriminação. Os problemas que envolvem as pessoas com deficiência parecem acompanhar o homem desde os primórdios de sua vida. Nesse sentido, para entender o presente, é necessário voltar ao passado e conhecer um pouco da história de luta das pessoas com deficiência ao longo dos tempos.

De acordo com Silva (2008), o entendimento, a atenção dispensada e as atividades desenvolvidas junto às pessoas com deficiência têm se transformado e se apresentado de diversas formas, de acordo com as diferentes épocas e culturas. Durante um longo período, as pessoas com deficiência tiveram suas "diferenças" associadas a um "sinal de desarmonia ou obra dos maus espíritos", como sinal de impureza ou pecado (CARMO, 1991). Ainda segundo o autor, tais apontamentos parecem revelar certa característica da natureza humana em desprezar o que aparentemente não Ihe gera benefícios imediatos, fechar os olhos para o que não consegue entender e ignorar o que acredita não ser de sua responsabilidade. Como recorda Rosadas (1991, p. 11), a este respeito:

[...] ao longo da história do homem sobre a terra, a deficiência física ou mental sempre existira e a rejeição ao deficiente vem sendo uma constante. Primitivamente matava-se física ou socialmente, pela segregação. Povos houveram, que fizeram dos deficientes abandonados à parte do templo ou isolados em uma instituição assistencial mantidos por esmolas, objetos de uma falsa caridade porque, através do dinheiro doado é que os mantinham isolados em um asilo. Comprava-se o conforto visual, o silêncio acusatório da consciência e pensava-se comprar o passaporte para o céu.

Outro exemplo de como eram tratadas as pessoas com deficiência na antiguidade, encontra-se na paráfrase de Sêneca, citada por Oto Marques da Silva (1987, p.129), em seu livro a Epopéia Ignorada: a pessoa deficiente na História do Mundo de ontem e de hoje:

Não se sente ira contra um membro gangrenado que se manda amputar; não o cortamos por ressentimento, pois tratase de um rigor salutar. Matam-se cães quando estão com raiva; exterminam-se touros bravios; cortam-se as cabeças das ovelhas enfermas para que as demais não sejam contaminadas; matam-se os fetos e os recémnascidos monstruosos; se nascerem defeituosos e monstruosos, afogamolos; não devido ao ódio, 
mas à razão, para distinguirmos as coisas inúteis das saudáveis.

Nos dias atuais, em plena Era da Inclusão Social, a luta das pessoas com deficiência não é mais para não serem eliminadas ou confinadas em masmorras, igrejas ou em instituições de caridade. Hoje, a luta é para que os seus direitos sejam plenamente garantidos e respeitados de acordo com as inúmeras legislações (leis, decretos, tratados, pareceres, convenções), internacionais e nacionais. Entre elas, destaca-se a Constituição Federal de 1988 e a Convenção Internacional dos Direitos das Pessoas com Deficiência, da qual o Brasil se tornou signatário desde 2009 e, mais recentemente, através da Lei № 13.146/2015, a chamada Lei Brasileira de Inclusão da Pessoa com Deficiência.

Medalha (2013), ao fazer referência a Constituição Federal, diz que é competência do Poder Público, representado pela União, Estados, Distrito Federal e Municípios, cuidar da Proteção e garantia das pessoas com deficiência. Todos os entes públicos têm o poder e o dever de adotar medidas administrativas necessárias para que a inclusão das pessoas com deficiência possa se efetivar. Em relação à participação do município nesse processo a autora relata que este:

$$
\begin{aligned}
& \text { [...] é o ente federativo } \\
& \text { mais próximo do cidadão e } \\
& \text { essa posição privilegiada } \\
& \text { oferece a oportunidade de } \\
& \text { ter adequadas as suas } \\
& \text { particularidades às } \\
& \text { políticas públicas e a } \\
& \text { produção de leis. Neste } \\
& \text { sentido, é possível ao } \\
& \text { município, legislar com } \\
& \text { fundamento no artigo } 30, \text { I } \\
& \text { da Constituição Federal, } \\
& \text { ou seja, quando por força } \\
& \text { da competência comum } \\
& \text { que lhe reservou o texto } \\
& \text { Constitucional, se tratar de } \\
& \text { assunto de interesse local. } \\
& \text { Desse modo, todas as } \\
& \text { iniciativas tendentes à } \\
& \text { inclusão das pessoas com } \\
& \text { deficiência na sociedade e } \\
& \text { na vida social, desde que } \\
& \text { observem as normas } \\
& \text { previstas na Constituição } \\
& \text { Federal e na Convenção } \\
& \text { internacional, serão } \\
& \text { incentivadas. (MEDALHA, } \\
& \text { 2003, p. 22) }
\end{aligned}
$$

Observando-se, assim, que todas as esferas do Poder Público possuem responsabilidades e, considerando que as pessoas "estão" nos municípios, compete a eles prover através de Políticas Públicas efetivas, suprir as necessidades de seus munícipes. Nesse sentido, tem ocorrido a preocupação de que os municípios efetivem diversas ações voltadas à inclusão das pessoas com deficiência. Afinal, se um

[...] Município para todos é aquele onde se praticam ações concretas visando à participação comunitária de todos os segmentos da população local; onde as pessoas podem circular livremente e em condições adequadas às suas limitações decorrentes da idade, de condições físicas ou sensorial; onde os idosos, jovens e deficientes são informados adequadamente sobre todos os serviços públicos colocados à sua disposição; onde a legislação municipal (Lei orgânica do município, plano diretor, leis orçamentárias, leis de parcelamento e uso do solo, código de obras e edificações, código de posturas, etc.), possa ser utilizada como instrumento de integração social e não como mecanismo de exclusão e opressão dessas pessoas. (SALLES, 2001, p. 57)

Desse modo, pode-se afirmar que, o Município tem fundamental responsabilidade nas ações realizadas pelos poderes locais no sentido de criar, estruturar e favorecer um ambiente necessário para, progressivamente, adotar e promover políticas públicas inclusivas com o intuito de incluir esse grupo de pessoas na comunidade (MEDALHA, 2013). Isto porque, acredita-se que desenvolver uma política de direitos às pessoas com deficiência é a melhor forma de possibilitar sua inclusão na sociedade, com participação ativa em todas as suas instâncias. 
Neste sentido, o presente artigo, objetiva apresentar algumas considerações sobre as contribuições das políticas públicas do Estado de São Paulo, referentes ao processo de inclusão das pessoas com deficiência e sua implementação nos municípios paulistas, pelo viés da Educação.

\section{METODOLOGIA}

O presente trabalho pauta-se em uma abordagem qualitativa, envolvendo uma pesquisa do tipo documental. A pesquisa documental caracteriza-se pela análise de documentos, neste caso, em específico, leis, decretos, portarias, tratados e convenções nacionais e internacionais que abordam a temática da inclusão da pessoa com deficiência. Cabe destacar que, segundo Phillips (1974 apud MENGA; ANDRÉ, 1986, p. 38) "são considerados documentos quaisquer materiais escritos que possam ser usados como fonte de informação sobre o comportamento humano", ou seja, "desde leis e regulamentos, normas, pareceres, cartas, memorandos, diários pessoais, autobiografias, jornais, até livros, estatísticas e arquivos escolares", que ainda não receberam nenhum tratamento analítico ou que ainda podem ser reelaborados de acordo com o projeto de pesquisa que se pretende realizar.

Vale destacar que, apesar da pesquisa ser pautada em sua maioria por documentos oficiais, buscou-se também contribuições nos mais diversos tipos de bibliografias sobre a história da pessoa com deficiência para poder explicar alguns conceitos, bem como para tentar encontrar as primeiras leis em que as pessoas com deficiência são mencionadas.

\section{RESULTADOS}

Diante do material analisado, até o momento, os resultados da pesquisa têm evidenciado o pioneirismo do Estado de São Paulo e de seus municípios, na implementação de instâncias na administração pública visando garantias de direitos às pessoas com deficiência, principalmente após o ano de 1984, como resultado do ano Internacional da Pessoa com Deficiência, proclamado pela Organização das Nações Unidas (ONU) no ano de 1981. Isto posto, verifica-se que São Paulo se tornou o primeiro Estado do País a implementar o Conselho Estadual dos Direitos da Pessoa com Deficiência.

Mais tarde, em dezembro de 2007, durante a gestão do Prefeito Gilberto Kassab, São Paulo se tornou o primeiro município brasileiro a implementar na administração pública direta, através da Lei N. 0 14.659, uma Secretaria Municipal para tratar de assuntos relacionados especificamente às pessoas com deficiência: Secretaria Municipal da Pessoa com Deficiência e Mobilidade Reduzida (SMPED).

Em Março de 2008, atendendo a reivindicação do Conselho Estadual e seguindo o exemplo do município, o Governador José Serra, promulgou a Lei Complementar N.ㅇ 1.038, instituindo a primeira Secretaria de Estado dos Direitos da Pessoa com Deficiência (SEDPCD) do país. Dessa forma, São Paulo, nas esferas estadual e municipal, assumiu uma posição de destaque nacional, servindo de referência a todos os demais.

Entre as diversas ações realizadas pela Secretaria de Estado dos Direitos das Pessoas com Deficiência, destaca-se ao menos três ações de incentivo aos municípios paulistas, objetivando a implementação de instância municipal específica e especializada, com foco na promoção dos direitos e inclusão da pessoa com deficiência. A primeira ação foi o envio de documento oficial, assinado pela Dra. Linamara Rizzo Battistella, Secretária de Estado dos Direitos da Pessoa com Deficiência de São Paulo, dirigido aos prefeitos dos 645 municípios paulistas, com o intuito de recomendar a importância da implementação de pelo menos uma instância municipal (secretaria, coordenadoria, diretoria ou assessoria) que tratasse de assuntos ligados às pessoas com deficiência. Tal recomendação foi, também, amplamente recomenda pelo Governador aos prefeitos municipais ao longo de suas reuniões e/ou encontros políticos.

Outra iniciativa pioneira no sentido de estimular os municípios a implementarem instâncias municipais com foco no desenvolvimento de políticas públicas de promoção e inclusão das pessoas com deficiência, foi a realização da Caravana da Inclusão, Acessibilidade e Cidadania. Lançada em 2010, através de uma parceria entre a Secretaria de Estado dos Direitos da Pessoa com Deficiência, a União de Vereadores do Estado de São Paulo (Uvesp) e a Rede Lucy Montoro, com apoio do Conselho Estadual para Assuntos da Pessoa com Deficiência (CEAPCD). A Caravana da Inclusão tinha o objetivo de mobilizar e conscientizar a sociedade, em especial prefeitos, vice-prefeitos, vereadores, autoridades municipais, gestores públicos, pessoas com deficiência, familiares e representantes da sociedade civil, para a necessidade de implementar e consolidar 
políticas públicas que contemplem os direitos de todas as pessoas com deficiência.

De acordo com a publicação da SEDPCD (SÃO PAULO, 2016), até o ano de 2016, em sua 7ạ edição, a Caravana já havia percorrido 69 municípios e registrado a participação de 300 gestores públicos, de aproximadamente 300 municípios paulistas. Ainda de acordo com a publicação, de 2010 a 2015, o número de instâncias específicas oficialmente implementadas pelos municípios paulistas saltou de 20 em 2010, para 152 em 2015.

A terceira ação realizada pela SEDPcD de incentivo aos munícipios paulistas, diz respeito a criação do Fórum Estadual de Secretários e Gestores Municipais dos Direitos das Pessoas com Deficiência. Considerada uma iniciativa inédita no país, a primeira edição do Fórum Estadual, foi realizada em agosto de 2015, na cidade de Capivari/SP, com o objetivo de estabelecer um intercâmbio de experiências entre os gestores, bem como a formulação de ações que incentivassem outros municípios paulistas a multiplicarem suas iniciativas e, também, criarem suas instâncias em prol dos direitos das pessoas com deficiência.

Durante o I Fórum Estadual, com a presença de gestores dos municípios que seguiram a recomendação da Secretaria de Estado dos Direitos da Pessoa com Deficiência e criaram uma instância municipal específica e especializada, com foco na promoção dos direitos e inclusão social das pessoas com deficiência, reconheceu-se e valorizou o trabalho dos mesmos, ao mesmo tempo em que reforçou a recomendação aos que ainda não haviam implementado uma instância.

Para melhor compreensão do que vem sendo descrito até o momento, traremos o exemplo da parceria entre as esferas governamentais, Estado e Município, que coaduna com tais apontamentos, ocorrida no município de Catanduva, localizado na região noroeste do Estado de São Paulo, a 387 quilômetros da capital.

Incentivado pela Secretaria de Estado dos Direitos das Pessoas com Deficiência, na última década, o município se tornou exemplo de boas práticas no que diz respeito à promoção e inclusão das pessoas com deficiência, através da implantação de importantes projetos e programas em diferentes áreas.

Em Junho de 2007, através da Lei N.응 4.410, ocorreu à instituição do Conselho
Municipal da Pessoa com Deficiência (CMPcD). Entre suas atribuições, no artigo 1 으 de seu estatuto, encontravam-se:

I - articular-se com órgãos
governamentais e não
governamentais de
planejamentorara ou
execução, nas políticas
voltadas para as pessoas
com deficiências,
objetivando uma atuação
integrada e eletiva; II - monitorar ações sociais relativas às pessoas com deficiências, visando subsidiar o cumprimento das normas legais existentes a elas pertinentes;

III - propor a implantação de diretrizes básicas da política municipal voltada à inclusão social das pessoas com deficiências;

IV - estimular e motivar a organização e mobilização dos segmentos interessados na problemática das pessoas com deficiências;

$\mathrm{V}$ - promover campanhas de conscientização direcionadas à sociedade em geral, especialmente junto às empresas, visando mostrar a potencialidade das pessoas com deficiência; VI - opinar sobre recursos financeiros destinados pelo município às instituições que tenham por objetivo o trato com pessoas com deficiências, e

VII - elaborar seu regimento interno disciplinando o seu funcionamento, com base na legislação vigente. (CATANDUVA, 2007).

Em decorrência de tais atribuições, bem como para atender as reivindicações tanto do CMPcD quando do moradores com deficiência do município de Catanduva, por meio da Lei $\mathrm{N}$.으 4.527, de 22 de abril de 2008, conquistou-se a criação do Dia Municipal da Pessoa com 
Deficiência, a ser comemorado, anualmente, no dia 20 de Agosto. Essas e outras ações contribuíram, diretamente, para a implantação em 2010, da Coordenadoria Municipal de Inclusão Social, órgão da administração pública municipal, ligado diretamente ao gabinete do Prefeito. Com o objetivo de desenvolver políticas públicas e atender as necessidades das pessoas com deficiência e idosos, a Coordenadoria de Inclusão Social foi criada através da Lei Complementar N.0549 de 2010.

Posteriormente a esta ação, e mediante o reconhecimento do trabalho desenvolvido pelo município, o Governo do Estado de São Paulo, através da Secretaria de Estado dos Direitos das Pessoas com Deficiência, escolheu Catanduva para implantar o primeiro Centro de Tecnologia e Inclusão Social do Estado de São Paulo. Desse modo, em 2011, foi celebrado o convênio entre Estado e Município, para a implantação do centro que, depois de inaugurado no ano de 2014, se tornou também a sede da Coordenadoria Municipal de Inclusão Social, constituindo um marco para a cidade e, em especial, para as pessoas com deficiência e seus familiares, tanto de Catanduva quanto das cidades vizinhas. O mesmo foi equipado com uma piscina coberta e aquecida, laboratório de informática, quadra poliesportiva coberta e iluminada, além de uma academia ao ar livre adaptada às pessoas com deficiência física.

Entre os programas e projetos desenvolvidos pelo município através do Centro de Tecnologia e inclusão Social, na área de Emprego e Renda, destaca-se o Programa municipal de empregabilidade da pessoa com deficiência, executado em parceria com a Secretaria Municipal de Desenvolvimento, Emprego e Relações do Trabalho. O programa foi idealizado, após reclamação dos empresários de que, não havia no município pessoas com deficiência disponíveis a serem contratadas pelas empresas. Apenas como exemplo, e contradizendo os empresários, o censo do IBGE (2010) apontava que dos 111.914 habitantes, aproximadamente 31.000 pessoas, declararam possuir algum tipo de deficiência. Em especial, no munícipio de Catanduva, na época, haviam cerca de aproximadamente 26.623 pessoas com deficiência.

Desse modo, o Programa de Empregabilidade da Pessoa com Deficiência, foi criado com o intuito de aproximar o candidato com deficiência da empresa, do empregador que necessitava contratar este profissional, para o cumprimento da Lei N. 0 8.213/91, a chamada Lei de Cotas. O Programa, portanto, consistia na criação de um banco de currículos on-line, onde as pessoas com deficiências interessadas poderiam cadastrar-se gratuitamente. Aos que não tinham acesso a um computador ou à internet, o cadastro poderia ser realizado presencialmente no Centro de Tecnologia e Inclusão Social. As empresas, por sua vez, tinham livre acesso ao banco de currículos e a todos os currículos cadastrados, facilitando dessa forma, todo o processo de análise, recrutamento e seleção de candidatos.

Um fator de importante destaque, conquistado ao longo da implantação do Programa de Empregabilidade, refere-se à identificação de que, apesar das leis de educação inclusiva, a maioria dos candidatos possuíam baixo grau de escolaridade e, consequentemente, pouca qualificação para o trabalho. Desta feita, o programa iniciou uma nova etapa: a qualificação das pessoas com deficiência, preferencialmente dos candidatos com currículos cadastrados no programa.

Nesse período, foram ofertados vários cursos: alguns realizados em parceria com empresas e instituições da cidade, como é o caso dos cursos de assistente administrativo e auxiliar administrativo com ênfase em qualidade e almoxarife; o Programa de Educação para o Trabalho - PET Trampolim ${ }^{1}$ e o curso de informática básica para pessoas com deficiência visual.

Em 2011 o reconhecimento por todas as conquistas ao longo dos primeiros anos do projeto chegou, por meio da inscrição do Programa no Prêmio Ações Inclusivas do Governo do Estado de São Paulo, realizado pela SEDPcD; onde foi classificado entre as cinco melhores práticas inclusivas do Estado, servindo de inspiração para outros municípios, reaplicarem a prática.

Outra iniciativa relevante, ligada à Educação, trata-se da elaboração da Cartilha Municipal de Orientação para a Educação Inclusiva - Todos pela Inclusão. Com o objetivo de proporcionar informações sobre os diferentes tipos de deficiência, o uso correto de terminologias inclusivas, além de dicas de como se comportar diante de pessoas com deficiência,

${ }^{1}$ Programa desenvolvido pelo Serviço Nacional de Aprendizagem Comercial - SENAC em parceria com a Prefeitura Municipal de Catanduva. 
a cartilha composta por 12 páginas, coloridas e com personagens criados para estimular a leitura e auxiliar na compreensão do conteúdo, foi distribuída gratuitamente para todos os professores da rede pública municipal de ensino e alunos das séries iniciais do ensino fundamental. Além disso, a cartilha foi disponibilizada no site da Prefeitura possibilitando a consulta e/ou download do material $^{2}$.

No esporte e lazer o município desenvolveu o Programa de Iniciação Esportiva para Pessoas com Deficiência, em parceria com a Secretaria Municipal de Esportes, Lazer e Turismo. O programa era voltado às pessoas com qualquer tipo de deficiência e as atividades propostas, realizavam-se de acordo com o interesse dos participantes. Nesse sentido, as atividades dividiam-se basicamente em duas turmas: a de treinamento, formada por atletas com o objetivo de representar o município em competições esportivas realizadas em nível local, regional e estadual, nas modalidades natação, atletismo e xadrez. E, na outra turma, pessoas que não desejavam participar de competições esportivas; para estes, a prática de atividades físicas tinham objetivos terapêuticos, de lazer e qualidade de vida, como por exemplo, a natação, - Goalball ${ }^{3}$, o xadrez, a hidroginástica, o alongamento, a ginástica funcional e a caminhada. Por meio deste Programa de iniciação esportiva foi possível observar o quanto o mesmo lhes proporcionou vários benefícios físicos, psicológicos, sociais e culturais, considerando que, muitos dos atletas só conheceram outras cidades, em virtude da participação em competições esportivas.

Em parceria com a Secretaria Municipal de Cultura, foi criada uma oficina de dança exclusiva para pessoas com deficiência. Com o tempo, diante do crescimento e do interesse pela oficina de dança, criou-se o Grupo de Dança Inclusiva 100 Fronteiras, constituído por pessoas com diferentes tipos de deficiência, idosos, além de jovens não deficientes. O grupo tornou-se uma grande atração na cidade e região, recebendo convites para se apresentarem em diferentes eventos e cidades, além de participar de festivais de dança.
$\mathrm{Na}$ área da acessibilidade, o município criou a CPA - Comissão Permanente de Acessibilidade, instituída pelo Decreto Municipal N. $-5.526 / 2010$, em cumprimento à Lei Federal N.o 10.048/2000, e o Decreto Federal N.ㅇ 5296/2004. Inicialmente, a CPA encontrava-se subordinada à Secretaria Municipal de Planejamento e Informática, com o objetivo de elaborar normas e controles que garantissem a acessibilidade de pessoas com deficiência ou com mobilidade reduzida, às edificações, vias e espaços públicos, transportes, mobiliários e equipamentos urbanos, bem como os meios de divulgação de informações e sinalizações relativas à acessibilidade. A Comissão era constituída por 16 membros, 8 representando o Poder Público, indicados pelo Prefeito Municipal, e 8 representando a sociedade civil, incluindo pessoas com

deficiência. Mais tarde, por iniciativa do Decreto N. 6.028 , de 15 de dezembro de 2011, a CPA passou a ser subordinada à Coordenadoria Municipal de Inclusão Social, mantendo os mesmos objetivos.

\section{DISCUSSÃO}

Diante do exemplo apresentado, observase que o processo de inclusão da pessoa com deficiência, como se tem observado neste artigo, depende da participação de todos os segmentos sociais, ou como descrito por Sassaki (1997, p.41), a inclusão é o "processo pela qual a sociedade se adapta para incluir em seus sistemas sociais gerais, pessoas com necessidades especiais e, simultaneamente, estas se preparam para assumir seus papéis na sociedade". Nesse sentido, o município por sua vez, ao implementar uma instância na administração pública direta, assume, se assim pode-se dizer, a responsabilidade de desenvolver ações concretas que possibilitem o acesso e a participação de todas as pessoas em todos os lugares e ambientes.

Para que isso de fato aconteça, é necessário o engajamento de toda a sociedade, em especial das autoridades locais: Prefeito, Viceprefeito, Secretários, Assessores, Diretores e Vereadores, pois é somente assim que conseguiremos implantar uma grande rede de serviços voltados à promoção e inclusão da pessoa com deficiência, em centenas de municípios paulistas, provocando mudanças estruturais, comportamentais e sociais, culminando com a participação mais efetiva das 
pessoas com deficiência na sociedade, como é previsto em nossa própria Constituição Federal e nas leis subsequentes.

A principal tarefa do município é atender as diferentes demandas da população e, nesse sentido, os serviços públicos considerados fundamentais, precisam ser planejados, considerando as necessidades de todas as pessoas com deficiência. Dessa forma, destaca-se a acessibilidade em suas diferentes modalidades: arquitetônica, atitudinal, comunicacional, instrumental, metodológica e programática. Remover os obstáculos existentes no meio urbano e nas edificações, de uso coletivo, construir calçadas acessíveis, instalar semáforos inteligentes e implantar rotas e faixas acessíveis, permitindo que a pessoa com deficiência se locomova com autonomia e segurança, é a garantia de um direito básico e fundamental do ser humano, o de ir e vir. Os transportes públicos, incluindo o transporte escolar e o transporte para usuários dos serviços de saúde, também precisam estar acessíveis e compete ao poder público prover essa condição. Afinal, se o transporte público não oferecer condições de acesso, a pessoa com deficiência naturalmente será privada de acessar outros serviços como, por exemplo, trabalho, saúde, educação.

Em relação ao trabalho e renda, o município deve criar condições favoráveis para que as pessoas com deficiência tenham acesso a programas de capacitação e qualificação profissional, estimular o emprego apoiado, além de promover ações de incentivo junto às empresas visando à inclusão de pessoas com deficiência no mercado de trabalho. Na área da saúde, o município deve oferecer serviços especializados com profissionais capacitados nas áreas de prevenção, tratamento e reabilitação física para atender as diferentes necessidades das pessoas com deficiência. A participação das pessoas com deficiência, em atividades esportivas, culturais e de lazer, também devem ser oportunizadas, respeitando suas particularidades.

Todavia, apesar das conquistas, com base nos dados atuais da Secretaria de Estado dos Direitos da Pessoa com Deficiência (2017), referente à implantação das instâncias, assim como das políticas públicas de inclusão, observou-se que, atualmente, apenas 29 municípios paulistas possuem, oficialmente, uma instância municipal específica para tratar de assuntos referentes à pessoa com deficiência.
Outros 70 municípios, apesar de não implantarem uma instância específica, desenvolvem ações, programas e projetos voltados ao tema, utilizam-se da estrutura administrativa de instâncias existentes no município, como por exemplo, nas Secretarias de Assistência Social ou da Educação.

O antigo número (152 municípios com instâncias), se comparado ao apresentado no documento da SEDPcD de 2016, expressa, portanto, uma significativa redução no número de municípios que implementaram e mantém uma instância específica para tratar de assuntos relacionados à pessoa com deficiência.

Isto posto, a primeira inferência que, acreditamos poder ser feita a respeito de tais dados contrastantes, refere-se a atual crise econômica e a fatores de ordem política que estão diretamente relacionados. Em relação ao fator econômico, vários municípios extinguiram suas instâncias, alegando a necessidade de cortar gastos e diminuir custos. Em relação à questão política, em virtude da troca de administração ocorrida por intermédio das eleições municipais, muitos dos gestores que estavam à frente das ações de inclusão nos municípios, foram remanejados de suas funções ou exonerados do cargo (no caso daqueles que ocupavam cargo em comissão).

Consideramos que, ao extinguir as secretarias, coordenadorias, diretorias ou assessorias, os municípios estão, de certa forma, causando um retrocesso nas Políticas Públicas que envolvem a inclusão da pessoa com deficiência na sociedade, assim, compete às pessoas com deficiência, familiares, instituições de apoio e, principalmente, aos conselhos municipais, cobrar e fiscalizar do executivo local, ações e projetos que garantam a igualdade de acesso e, principalmente, o usufruto de todos os bens, produtos e serviços, existentes na sociedade.

Por fim, acredita-se que a base para a construção de uma nova sociedade, de um município inclusivo, dá-se principalmente por meio da Educação. Ou seja, para se garantir o conjunto de direitos previstos nas políticas públicas, deve-se investir em ações educativas dentro e fora da escola. A educação inclusiva deve ser prioridade e estar pautada nos quatro princípios estabelecidos pela Lei Brasileira de Inclusão da Pessoa com Deficiência: acesso, permanência, aproveitamento e aprendizagem, pois só assim a pessoa com deficiência deve 
encontrar, na sociedade, condições adequadas para o seu desenvolvimento através de sua educação e qualificação para o trabalho.

\section{REFERÊNCIAS}

BRASIL. Congresso Nacional. Lei №. 8.213, de 24 de julho de 1991. Dispõe sobre os planos de benefícios da Previdência Social e dá outras providências. Diário Oficial da União, Brasília-DF, 25 jul. 1991. Disponível em: http://www.planalto.gov.br/ccivil 03/leis/L8213c ons.htm>. Acesso em: 24 jan. 2018.

BRASIL. Congresso Nacional. Lei brasileira de Inclusão. Lei №. 13.146, de 06 de Julho de 2015. Institui a Lei Brasileira de Inclusão da Pessoa com deficiência. Diário Oficial da União, Brasília-DF, 07 jul. 2015. Disponível em: http://www.planalto.gov.br/ccivil 03/ ato20152018/2015/lei/l13146.htm>. Acesso em: 10 out. 2017.

CATANDUVA. Lei №. 4410, de 05 de junho de 2007. Dispõe sobre a criação do Conselho Municipal da Pessoa com Deficiência - CMPCD e dá outras providências. Imprensa Oficial, São Paulo-SP, 05 jun. 2007. Disponível em: http://leis.catanduva.sp.gov.br:8080/sapl/consult as/norma juridica/norma juridica mostrar proc ?cod norma=4921 . Acesso em: 25 jan. 2018.

CATANDUVA. Decreto №. 5526, de 19 de abril de 2010. Institui a Comissão Permanente de Acessibilidade - CPA e dá outras providências. Imprensa Oficial, São Paulo-SP, 30 abr. 2010. Disponível em: http://leis.catanduva.sp.gov.br:8080/sapl/consult as/norma juridica/norma juridica mostrar proc ?cod norma=12009. Acesso em: 24 jan. 2018.

CATANDUVA. Lei Complementar №. 0549, 08 de setembro de 2010. Autoriza a criação da Coordenadoria Municipal de Inclusão Social e cargos na Administração Pública Municipal e dá outras providências. Imprensa Oficial, São PauloSP, 17 set. 2010. Disponível em: http://leis.catanduva.sp.gov.br:8080/sapl/consult as/norma juridica/norma juridica mostrar proc ?cod norma=12289. Acesso em: 24 jan. 2018.

CATANDUVA. Decreto №. 6028, de 15 de dezembro de 2011. Dá nova redação a dispositivos do Decreto № 5526, de 19 de abril de 2010, que institui a Comissão Permanente de
Acessibilidade - CPA e dá outras providências. Imprensa Oficial, São Paulo-SP, 23 dez. 2011. Disponível em: http://leis.catanduva.sp.gov.br:8080/sapl/consult as/norma juridica/norma juridica mostrar proc ?cod norma=12888. Acesso em: 24 jan. 2018.

CATANDUVA. Lei №. 4547, de 22 de abril de 2008. Dispões sobre a instituição do dia Municipal da Pessoa com Deficiência e dá outras providências. Imprensa Oficial, São Paulo-SP, 02 mai. 2008. Disponível em: http://leis.catanduva.sp.gov.br:8080/sapl/consult as/norma juridica/norma juridica mostrar proc ?cod norma=11067. Acesso em: 25 jan. 2018.

DESLANDES, S. F. A Construção do Projeto de pesquisa. In: MINAYO, M. C. S. et al (org). Pesquisa Social: Teoria, método e criatividade. 23a ed. Petrópolis: Ed. Vozes, 2004, p.31-50.

FÁVERO, E. A. G. Direitos das pessoas com deficiência: garantia de igualdade na diversidade. Rio de Janeiro: WVA, 2004.

GARCIA, R. M. C. Políticas públicas de inclusão: uma análise no campo da educação especial brasileira. 2004. 216f. Tese (Doutorado em Educação) - Universidade Federal de Santa Catarina, Santa Catarina, 2004.

LEAL, D. (Org). História, memória e práticas da inclusão escolar. Curitiba: InterSaberes, 2017.

LÜDKKE, M.; ANDRÉ, M. E. D. A. Pesquisa em Educação: Abordagens qualitativas. São Paulo: EPU, 1986.

MEDALHA, M. Direitos e Garantias das Pessoas com deficiência: a atuação do município. São Paulo: Cepam, 2013.

OLIVEIRA, J. B. G. A perspectiva da inclusão escolar da pessoa com deficiência no Brasil: um estudo sobre as políticas públicas. Revista Tempos e Espaços em Educação, São Cristóvão, Sergipe, v.4, n.6, p. 147-159, jan/jun. 2011.

PESSOTI, I. Deficiência Mental: da superstição à ciência. São Paulo: Ed. da Universidade de São Paulo, 1984.

ROSADAS, S. C. Educação Física Especial para Deficientes. 3. ed. Rio de Janeiro: Atheneu, 1991. 
SÃO PAULO. Relatório mundial sobre a deficiência. São Paulo: SEDPcD, 2012.

SÃO PAULO. 7a Caravana da Inclusão, acessibilidade e cidadania. São Paulo: SEDPCD, 2016.

SALLES, L. R. Município Acessível ao Cidadão. São Paulo: Fundação Faria Lima - Cepam/ Sebrae, 2001.

SASSAKI, R. T. Construindo uma sociedade para todos. 7. ed. Rio de Janeiro: WVA, 1997.

SETUBAL, J. M.; FAYAN. R. A. C. (Orgs). Lei Brasileira de Inclusão da Pessoa com Deficiência - Comentada. 1. ed. rev. Campinas: Fundação FEAC, 2017.

SILVA, M. I. LBI na Prática: a Lei Brasileira de Inclusão na vida cotidiana das pessoas com deficiência. São Paulo: SEDPcD, 2016.

SILVA, O. M. A Epopéia Ignorada: A Pessoa deficiente na história do mundo de ontem e hoje. São Paulo: Cedas, 1986.

SILVA, R. F.; SEABRA JÚNIOR, L.; ARAÚJO, P. F. Educação Física Adaptada no Brasil: da história à inclusão educacional. São Paulo: Phorte, 2008.

Recebido para publicação em: 04/11/2017

Revisado em: 31/01/2018

Aceito em: 09/03/2018 